\title{
Analisis Proses Pengendalian Mutu Standar Pelayanan Minimal (SPM) di Instalasi Farmasi RS Keluarga Sehat
}

\author{
Lia Alfa Rosida*, Sudiro** \\ *Alumni Magister Ilmu Kesehatan Masyarakat Universitas Diponegoro, **Staf Pengajar Program \\ Magister Ilmu Kesehatan Masyarakat Universitas Diponegoro \\ Email: liaalfar@yahoo.com
}

\section{ABSTRACT}

The indicator achievement of minimum service standard (MSS) for the accuracy of distributingdrugs in Pharmacy Unit of Keluarga Sehat Hospital has not been achieved, even the incidence ofthe distributionerror from 2013 to 2016 continues to increase. The purpose of this researchwas to analyze the quality control process in the implementation of MSS in Pharmacy Unit of Keluarga Sehat Hospital. This was a qualitative research, with research subject 3pharmacy officers and 3 people of pharmacy management services.Data collectedby in-depth interview and observation of pharmaceutical performance report data and analysed by content analysis. The result of the research showed that the evaluation of pharmacy staff performance has not been implemented, because there is no performance appraisal indicator yet. Comparison was done only by comparing reports with general target, medical support manager double job resulted in no feedback to Pharmacy Unit, and so it has not supported the implementation of MSS. The Improvement of performancehas not been implementedand has notfound the concept of improvement. The new management will attempt to conduct a comparative study, including pharmacy installation into the Quality Control Group
(GKM) or Problem Solving for Better Health (PSBH), find the cause of the problem and develop the policy. It can be concluded that the quality control of the MSS in the Pharmacy Unit still not going well and need to be improved especially related to quality performance appraisal and performance improvement based on the SOP.

Keywords: Quality Control; Pharmacy Installation; Minimum Service Standards (MSS)

\section{PENDAHULUAN}

Keputusan Menteri Kesehatan Nomor 129/Menkes/SK/II/2008 tentang Standar pelayanan minimal (SPM) rumah sakit digunakan sebagai pedoman bagi rumah sakit dalam menjamin pelaksanaan pelayanan kesehatan1. Terkait hal tersebut RS Keluarga Sehat telah melaksanakan SPM, salah satunya adalah SPM instalasi instalasi farmasi. ${ }^{1}$

SPM farmasi sebagai sasaran mutu yang harus dicapai dalam kurun waktutiga tahun, dimana hasil capaian sasaran mutu instalasi farmasi yang belum dapat memenuhi adalah pencapaian indikator tidak adanya kejadian kesalahan pemberian obat. Data capaian SPM instalasi farmasi dari tahun 2013 sampai dengan 2016 dapat dilihat pada tabel 1 . 
Tabel 1 Capaian SPM IFRS Keluarga Sehat

\begin{tabular}{|c|c|c|c|c|c|c|}
\hline \multirow[t]{2}{*}{ No } & \multirow[t]{2}{*}{ Indikator SPM } & \multicolumn{4}{|c|}{ Rata-rata Pencapaian (\%) } & \multirow{2}{*}{$\begin{array}{c}\text { Standar } \\
\text { Pencapaian }\end{array}$} \\
\hline & & $\begin{array}{l}\text { Tahun } \\
2013\end{array}$ & $\begin{array}{l}\text { Tahun } \\
2014\end{array}$ & $\begin{array}{l}\text { Tahun } \\
2015\end{array}$ & $\begin{array}{l}\text { Tahun } \\
2016\end{array}$ & \\
\hline \multirow[t]{3}{*}{1} & $\begin{array}{l}\text { Waktu tunggu } \\
\text { pelayanan: }\end{array}$ & & & & & \\
\hline & $\begin{array}{l}\text { a. Obat jadi: } \leq 30 \\
\text { menit }\end{array}$ & 91 & 91 & 92 & 94 & $90 \%$ \\
\hline & $\begin{array}{l}\text { b. Obat Racikan: } \leq 60 \\
\text { menit }\end{array}$ & 90 & 90 & 91 & 93 & $90 \%$ \\
\hline 2 & $\begin{array}{l}\text { Tidak adanya kejadian } \\
\text { kesalahan pemberian } \\
\text { obat }\end{array}$ & $\begin{array}{l}10 \text { kasus } \\
\text { KTD }\end{array}$ & $\begin{array}{l}12 \text { kasus } \\
\text { KTD }\end{array}$ & $\begin{array}{l}15 \text { kasus } \\
\text { KTD }\end{array}$ & $\begin{array}{l}20 \text { kasus } \\
\text { KTD }\end{array}$ & $\begin{array}{l}100 \% \text { atau } 0 \\
\text { kasus }\end{array}$ \\
\hline 3 & Kepuasan Pelanggan & 85 & 89 & 92 & 96 & $\geq 80 \%$ \\
\hline 4 & $\begin{array}{l}\text { Penulisan resep sesuai } \\
\text { formularium }\end{array}$ & 95 & 98 & 100 & 100 & $100 \%$ \\
\hline
\end{tabular}

Sumber data prasurvey: Laporan Mutu Instalasi Farmasi RS Keluarga Sehat Pati

Berdasarkan data tersebut dari tahun 2013 sampai dengan tahun 2016 untuk indikator tidak adanya kejadian kesalahan pemberian obat trendnya meningkat. Hal ini menjadi permasalahan penting karena kepuasan dan keselamatan pasien tidak tercapai yang mengakibatkan kerugian baik dari pihak manajemen maupun pasien.

Pengendalian mutu instalasi farmasi RS Keluarga Sehat dibutuhkan peran manajemen rumah sakit dalam manajemen mutu. Salah satu tokoh yang menyumbangkan pemikirannya dalam manajemen mutu adalah J.M. Juran. Pengendalian mutu (Quality Control) menurut J.M. Juran terdiri dari kegiatan evaluasi kinerja mutu aktual, perbandingan kinerja aktual tersebut dengan tujuan dan melakukan perbaikan berdasarkan perbedaan antara kinerja dan tujuan $^{2,3}$.Tujuan penelitian ini adalah menganalisis proses pengendalian mutu Juran dalam pelaksanaan SPM di Instalasi Farmasi RS Keluarga Sehat yaitu evaluasi kinerja mutu aktual, perbandingan kinerja dengan tujuan dan perbaikan.

\section{METODE PENELITIAN}

Penelitian ini merupakan jenis penelitian observasional dengan pendekatan kualitatif dan disajikan secara deskriptif . Penelitian dilakukan ada bulan Januari - Maret 2017 yang berlokasi di RS
Keluarga Sehat. Variabel penelitian adalah pengendalian mutu dan pencapaian SPM. Pengumpulan data dilakukan dengan wawancara mendalam, observasi dengan menggunakan checklist dan telaah dokumen. Subjek penelitian terdiri dari informan utama yaitu sebanyak tiga orang, yaitu: Tenaga Teknis Kefarmasian (TTK), pembantu TTK dan Apoteker. Informan triangulasi sebanyak tiga orang yaitu: Direktur, Deputy Direktur Yanmed dan Manajer Penunjang Medis. Selanjutnya data diolah kemudian dianalisis dengan menggunakan content analysis.

\section{HASIL DAN PEMBAHASAN SPM Instalasi Farmasi RS Keluarga Sehat}

Sasaran mutu yang ditetapkan oleh Direktur rumah sakit untuk instalasi farmasi adalah pencapaian SPM. Dari empat indikator yang belum tercapai yaitu pelaksanaan ketepatan pemberian obat rata-rata pencapaian ketepatan pemberian obat dari tahun 2013 sampai 2016 sebesar 99,987\% (rata-rata ada kejadian kesalahan pemberian obat 14 kejadian setiap tahun).

\section{Pelaksanaan Ketepatan Pemberian Obat}

Pelaksanaan SPM ketepatan pemberian obat di instalasi farmasi RS Keluarga Sehat dilakukan dengan cara 
melakukan pelayanan farmasi sesuai dengan standar prosedur operasional (SPO) di instalasi farmasi yaitu SPO pengkajian resep dan SPO pelayanan resep. Pengkajian resep harus dilakukan oleh petugas farmasi sesuai dengan SPO pengkajian resep yang meliputi pengkajian persyaratan administrasi, persyaratan farmasetik/ sediaan, dan persyaratan klinis. Pelayanan resep dimulai dari penerimaan resep, pemeriksaan ketersediaan, penyiapan sediaan farmasi termasuk peracikan obat, pemeriksaan obat, penyerahan disertai pemberian informasi yang harus dilakukan oleh petugas farmasi sesuai dengan SPO pelayanan resep di instalasi farmasi. Pada tahap pengkajian resep kendala yang dihadapi petugas farmasi adalah kesulitan membaca tulisan resep dokter (tulisan tidak jelas/ tidak terbaca/ ambigu) sesuai dengan SPO yang ada di instalasi farmasi, petugas farmasi melakukan konfirmasi ke dokter penulis resep untuk memastikan kebenaran obat yang dituliskan pada resep dan petugas mengisi form cek list resep dikolom konsulan dokter, sebagai bukti sudah dilakukan konfirmasi terkait tulisan resep yang sulit dibaca.

Tahap pelayanan resep selanjutnya adalah menyiapkan obat sesuai resep, petugas farmasi setiap tahap alur pelayanan resep dilakukan upaya pencegahan terjadinya kesalahan pemberian obat (medication error) dengan melakukan kroscek antara petugas farmasi. Akan tetapi dalam pelaksanaannya masih ada kejadian kesalahan pemberian obat. Hal ini disebabkan karena petugas farmasi kurang konsentrasi dikarenakan ruang pelayanannya yang tidak nyaman sehingga tidak dapat melaksanakan pelayanan sesuai standar prosedur operasional yaitu melakukan kelalaian dalam pengkajian resep maupun kroscek antar petugas farmasi pada setiap tahap alur pelayanan resep.

Persentase ketepatan pemberian obat dilakukan dengan menghitung kejadian kesalahan pemberian obat dibandingkan dengan jumlah resep yang dilayani. Data tahun 2013 sampai dengan 2016 trennya meningkat dari mulai tahun 2013 sampai tahun 2016. Rata-rata ketepatan pemberian obat pencapaiannya 99,987\%. Masalah kesalahan pemberian obat ini merupakan permasalahan mendasar yang harus diutamakan dalam pelayanan di rumah sakit. Organisasi kesehatan dunia WHO juga telah menegaskan pentingnya keselamatan dalam pelayanan kepada pasien: "Safety is a fundamental principle of patient care and a critical component of quality management." (World Alliance for Patient Safety, Forward Programme WHO, 2004). Meskipun angka pencapaiannya hanya kurang $0,013 \%$, akan tetapi hal ini menyangkut keselamatan pasien sehingga perlu perhatian serius untuk tindaklanjut perbaikannya. Penyebab tidak tercapainya ketepatan pemberian obat petugas farmasi tidak melaksanakan pelayanan sesuai standar prosedur operasional yaitu melakukan kelalaian dalam pengkajian resep maupun kroscek antar petugas farmasi pada setiap tahap alur pelayanan resep.

\section{Evaluasi Kinerja Mutu Aktual dalam Pelaksanaan Ketepatan Pemberian Obat}

Evaluasi kinerja mutu aktual petugas farmasi berkaitan dengan pelaksanaan SPO dalam mendukung ketepatan pemberian obat belum pernah dilakukan. Hal ini bisa diketahui bahwa manajemen belum melakukan evaluasi kinerja terhadap mutu aktual, sebagaimana dikatakan oleh Direktur.

"Evaluasi kinerja petugas belum dilakukan, seharusnya memang ada. Saat ini juga belum ada evaluasi khusus, unit hanya melaporkan kegiatan setiap bulan termasuk SPM.

\begin{tabular}{rll} 
& & (Inf Triangulasi 1) \\
\hline Evaluasi khusus unit menurut
\end{tabular} apoteker dan Depdir Yanmed belum dilakukan, evaluasi yang dimaksud adalah evaluasi secara keseluruhan terhadap kinerja. Evaluasi kinerja adalah suatu metode dan proses penilaian dan 
pelaksanaan tugas seseorang atau sekelompok orang atau unit-unit kerja dalam satu perusahaan atau organisasi sesuai dengan standar kinerja atau tujuan yang ditetapkan lebih dahulu. Hal ini terlihat bahwa manajemen hanya melihat hasil akhir bahwa hasil belum sesuai dengan target atau tujuan, tidak dilakukan evaluasi penyebab tidak tercapainya target. Evaluasi seharunya dilakukan secara berkesinambungan agar sesuai dengan tujuan evaluasi. Tujuan evaluasi kinerja adalah untuk menjamin pencapaian sasaran dan tujuan perusahaan dan juga untuk mengetahui posisi perusahaan dan tingkat pencapaian sasaran perusahaan, terutama untuk mengetahui bila terjadi keterlambatan atau penyimpangan supaya segera diperbaiki, sehingga sasaran atau tujuan tercapai.

Evaluasi kinerja mutu aktual petugas farmasi dalam mendukung pelaksanaanketepatan pemberian obat berkaitan dengan pelaksanaan SPO di instalasi farmasi RS Keluarga Sehat, diperoleh ketidaksesuaian bahwa evaluasi kinerja mutu aktual petugas farmasi belum mendukung pelaksanaanketepatan pemberian obat yang berkaitan dengan pelaksanaan SPO di instalasi farmasi RS Keluarga Sehat.Hal ini bisa diketahui bahwa manajemen belum melakukan evaluasi secara khusus terhadap mutu aktual petugas farmasi meskipun SPO yang mendukung ketepatan pemberian obat sudah ada dan tersosialisasi, sebagaimana diungkapkan oleh apoteker, manajer penunjang medisdan Depdir Yanmed.

"SPO pelayanan farmasi yang mendukung pelaksanaan ketepatan pemberian obat sudah ada dan sudah disosialisasikan”.

(Inf Utama1, Inf Triangulasi 2\&3)

Hal ini sesuai dengan pendapat Tambunan yang menyatakan bahwa SPO pada dasarnya adalah pedoman yang berisi prosedur-prosedur operasional standar yang ada di dalam suatu organisasi yang digunakan untuk memastikan bahwa setiap keputusan, langkah, atau tindakan, dan penggunaan fasilitas pemrosesan yang dilaksanakan oleh orang-orang di dalam suatu organisasi telah berjalan secara efektif, konsisten, standar dan sistematis. ${ }^{4}$

Dengan ditetapkannya SPO yang mendukung ketepatan pemberian obat, maka kemungkinan kejadian kesalahan pemberian obat dapat diantisipasi. Apoteker, TTK, pembantu TTK maupun Manajer Penunjang Medis menyatakan bahwa setiap brifing pagi koordinator pelayanan mengingatkan agar memberikan pelayanan sesuai SPO, yaitu selalu kroscek antar petugas farmasi .

"Koordinator pelayanan setiap brifing pagi mengingatkan agar memberikan pelayanan sesuai $S P O$, yaitu selalu kroscek antar petugas farmasi.

(Inf Utama 1,2 \&3, Inf Triangulasi 3)

Hal ini sesuai dengan pendapat Falino yang menyatakan bahwa brifing adalah sebuah latihan untuk menanamkan informasi yang relevan dan pesan perusahaan dalam kelompok. Brifing juga menjadi alat yang efektif akan komunikasi dua arah antara tim dan perusahaan. Brifing adalah sebuah proses komunikasi di mana manajer memberikan pengarahan pada timnya sehingga mereka dapat melangkah bersama sejalan dengan perubahan nilai dan kondisi tempat kerja. ${ }^{5}$

\section{Perbandingan Kinerja dalam Pelaksanaan Ketepatan Pemberian Obat}

Perbandingan kinerja dalam mendukung pelaksanaanketepatan pemberian obat berkaitan dengan pelaksanaan SPO di instalasi farmasi RS Keluarga Sehat, belum pernah dilakukan oleh manajemen. Depdir Yanmed menyampaikan bahwa tidak ada indikator penilaian yang jelas.

"Belum ada indikator atau ukuran penilaian yang jelas"

(Inf Triangulasi 2) 
Hal ini sesuai dengan pendapat Moeheriono yang menyatakan bahwa indikator kinerja sebagai nilai atau karakteristik tertentu yang dipergunakan untuk mengukur output atau outcome suatu kegiatan. Indikator kinerja juga sebagai alat ukur yang dipergunakan untuk menentukan derajat keberhasilan suatu organisasi dalam mencapai tujuannya, sebagai ukuran kuantitatif dan kualitatif yang menggambarkan tingkat pencapaian suatu sasaran atau tujuan yang telah ditetapkan oleh organisasi. ${ }^{6} \mathrm{Di}$ instalasi farmasi, indikator penilaian kinerja secara umum hanya berupa target yang harus dicapai, sedangkan indikator penilaian kinerja petugas belum ada. Adapun indikator penilaian kinerja yang dimaksud oleh informan triangulasi tiga adalah indikator penilaian sesuai dengan tugas fungsi masing-masing, baik tugas utama ataupun tugas tambahan sebagai koordinator pelayanan, pelaksana. Indikator kinerja inilah yang belum ada di instalasi farmasi.

Direktur, Depdir Yanmed dan Manajer Jangmed menyatakan bahwa hasil kinerja diketahui dari laporan bulanan dan belum ada umpan balik dari laporan bulanan yang dilakukuan oleh manajemen.

"Saat ini hanya membandingkan laporan bulanan unit dan belum ada umpan balik terhadap hasil laporan".

(Inf T riangulasi 1, 2,3)

Laporan yang diberikan oleh instalasi farmasi adalah berupa data kerja selama satu bulan. Dari laporan tersebut belum pernah ada umpan balik atau analisa data yang dilakukan oleh pihak manajemen. Padahal umpan balik berupa analisa data sangat diperlukan guna menentukan langkah-langkah perbaikan. Hal ini sesuai dengan pendapat Moeheriono yang menyatakan bahwa data yang dibutuhkan untuk mengukur dan mengawasi kinerja saling terkait dengan indikator dan target yang dipilih. Meski data harus terkait dengan indikator dan target, tetapi tidak jarang indikator dan target direvisi sesuai dengan ketersediaan data. 6

Apoteker dan Manajer Jangmedmenyatakan bahwa seharusnya manajemen ikut mengontrol aktivitas di tingkat instalasi,

"Seharusnya manajemen ikut mengontrol aktifitas di farmasi, kalau hanya membaca dari laporan bulanan tanpa tindak lanjut ya percuma."

(Inf Utama 1, Inf Triangulasi 3)

Top manajemen adalah eksekutif dengan tanggung jawab yang luas, namun tidak terkait langsung dengan strategi dan kebijakan bisnis perusahaan namun berkontribusi dalam pengesetan dan sangat berpengaruh pada implementasi strategi fungsional. Top manajemen berperan mengarahkan dan mengontrol aktivitas dalam suatu organisasi untuk sebuah fungsi atau produk. ${ }^{7}$ Top manajemen yaitumanager penunjang medis di RS Keluarga Sehat, tidak ikut mengontrol aktifitas secara langsung, dikarenakan manager penunjang medis memegang dua tanggungjawab yaitu merangkap sebagai manager keuangan yang sudah tiga tahun ini kosong belum ada penggantinya, sehingga hanya melalui laporan bulanan yang disampaikan oleh pihak asisten manager farmasi setiap bulan. Manajemen tidak memberikan langkah-langkah strategi yang harus diambil oleh instalasi farmasi guna memenuhi target yang harus dicapai. Apoteker dan Manajer Jangmed juga menambahkan bahwa belumpernah mengadakan pertemuan dengan manajemen untuk membahas hal ini.

"Belum pernah ada pertemuan atau komunikasi dengan manajemen untuk membahas hal ini, mungkin setelah ini nanti kita akan coba adakan pertemuan"

(Inf Utama 1, Inf Triangulasi 3)

Hal ini sesuai dengan pendapat
Siagian yang menyatakan bahwa


pemeliharaan hubungan dengan karyawan memerlukan komunikasi yang efektif, melalui komunikasi berbagai hal yang menyangkut kehidupan organisasi disampaikan oleh suatu pihak ke pihak yang lain. Komunikasi merupakan wahana bagi manajemen untuk menyampaikan berbagai hal kepada para bawahannya, seperti perintah, instruksi, kebijaksanaan baru, pengarahan, pedoman kerja, nasehat dan teguran. Kesemuanya itu dalam rangka usaha manajemen untuk lebih menjamin bahwa tindakan, sikap dan perilaku karyawan sedemikian rupa sehinga kemampuan organisasi untuk mencapai tujuan dan berbagai sasarannya semakin meningkat. ${ }^{8}$

TTK dan pembantu TTK menyatakan bahwa salah satu penyebab kejadian kesalahan pemberian obat dikarenakan petugas kurang konsentrasi atau teledor penyebabnya ruang kerja tidak nyaman.

"Salah satu penyebab bekerja tidak konsentrasi, ruang kerja tidak nyaman"

(Inf U tama 2, 3)

Kondisi petugas farmasi yang bekerja tidak konsentrasi dan teledor disebabkan penataan ruang dan fasilitas yang kurang sesuai dengan desain yang memudahkan dalam pelayanan din instalasi farmasi. Hal ini tidak bisa dibiarkan begitu saja karena akan mengakibatkan pelayanan terganggu. Peneliti mengusulkan untuk menata ulang fasilitas dan prasarana yang dibutuhkan dan disesuaikan dengan lay out ruangan sehingga memudahkan dalam penataan obat dan memudahkan pengambilan obat dalam aliran pelayanan farmasi.

\section{Perbaikan Kinerja Dalam Mendukung Pelaksanaan Ketepatan Pemberian Obat Berkaitan Dengan Pelaksanaan SPO}

Perbaikan perbedaan kinerja dalam mendukung pelaksanaan ketepatan pemberian obat berkaitan dengan pelaksanaan SPOdi instalasi farmasi RS Keluarga Sehat belum dilakukan oleh manajemen. Pihak manajemen tidak dapat melakukan perbaikan karena tahapan evaluasi kinerja petugas juga belum dilaksanakan sehingga manajemen tidak tahu bagian mana yang harus diperbaiki.

Apoteker dan TTK menyatakan bahwa koordinator pelayanan menegur petugas farmasi yang tidak sesuai dengan SPO pelayanan. Direktur, Depdir Yanmed dan Manajer Jangmed sependapat agar lebih efektif dalam perbaikan, harus ada teguran baik lisan maupun tertulis atau berupa hukuman bagi yang bekerja tidak sesuai SPO sehingga tidak terjadi kesalahan pemberian obat.

"Harusnya manajemen menegur atau memberi peringatan kalau ada petugas yang bekerja tidak sesuai SPO”

(Inf Triangualasi 1, 2,

Hal ini sesuai dengan pendapat Siagian (2006) yang menyatakan bahwa jika ada karyawan yang nyata-nyata melakukan pelanggaran atas ketentuanketentuan yang berlaku atau gagal memenuhi standar yang telah ditetapkan, kepadanya dikenakan sanksi ${ }^{8}$. Berat atau ringannya suatu sanksi tergantung pada bobot pelanggaran yang telah terjadi. Pengenaan sanksi biasanya mengikuti prosedur yang sifatnya hierarki, artinya pengenaan sanksi diprakarsai oleh atasan langsung yang bersangkutan kemudian diteruskan ke pimpinan yang lebih tinggi. Pengenaan sanksi harus bersifat mendidik dalam arti agar terjadi perubahan sikap dan perilaku di masa depan dan bukan terutama menghukum seseorang karena tindakannya di masa lalu ${ }^{8}$.Di instalasi farmasi, manager penunjang medis tidak pernah memberikan teguran atau peringatan kalau ada petugas yang bekerja tidak sesuai SPO, pemberian teguran hanya melalui kepala instalasi farmasi.

Direktur, Depdir Yanmed dan Manajer Jangmed menyatakan bahwa, untuk perbaikan kalau diperlukan 
dilakukan studi banding .

"Kalau memang diperlukan, mungkin nanti diadakan studi banding ke rumah sakit lain.."

(Inf Triangulasi 1, 2, 3)

Hal ini sesuai dengan pendapat Sunyoto D, Wahyudi D yang menyatakan bahwa benchmarking adalah usaha untuk melakukan kegiatan dengan menggunakan perusahaan lain yang dianggap terbaik. Benchmarking ini biasanya mengarah kepada upaya pencarian yang terbaik untuk bidang tertentu, misalnya berupa kualitas komponen, produk atau proses dalam kelasnya sebagai patokan. ${ }^{9}$ Studi banding ke rumah sakit lain yang sudah memenuhi target dalam pelaksanaan SPM, baru merupakan wacana yang disampaikan oleh informan, dan hal ini juga belum pernah direncanakan, seharusnya segera melaksanakan studi banding atau benchmarking untuk mempelajari agar SPM bisa tercapai .

Direktur, Depdir Yanmed dan Manajer Jangmed juga menyatakan bahwa instalasi farmasi diikutkan ke dalam Gugus Kendali Mutu (GKM) atau Problem Solving For Better Health (PSBH).

"Mengikuti kegitan PSBH yang diadakan oleh rumah sakit”.

(Inf Triangulasi 1, 2, 3)

Hal ini sesuai dengan pendapat Wijono yang menyatakan bahwa Gugus Kendali Mutu (GKM) atau Quality Control Circle adalah sekelompok kecil petugas yang secara sukarela melakukan kegiatankegiatan pengendalian mutu di dalam tempat kerjanya sendiri dengan tujuan untuk mencari pemecahan permasalah (problem solving) terhadap persoalanpersoalan yang menonjol yang ada di tempat kerjanya. ${ }^{10}$

Direktur menyatakan bahwa perbaikan sebaiknya dicari penyebab masalahnya dan dibuat kebijakan. "upayannya..kita mencari penyebab masalahnya dulu, kemudian kita rapatkan atau dibicarkan pada waktu morning meeting manajemen, kemudian dibuat kebijakan"

(Inf Triangulasi

1)

Hal ini sesuai dengan pendapat Wijonoyang menyatakan bahwa untuk memecahkan adanya masalah mutu pelayanan dilakukan identifikasi masalah, menetapkan masalah, mencari penyebab utama timbulnya masalah, memilih cara pemecahan masalah, kemudian melaksanakan solusi pemecahan masalah. ${ }^{10}$

\section{KESIMPULAN}

Kesimpulan penelitian ini adalah majemen belum melakukan evaluasi kinerja mutu aktual petugas farmasi berkaitan dengan pelaksanaan SPO dari data laporan kinerja bulanan unit. Hal ini dikarenakan belum ada indikator penilaian kinerja petugas farmasi meskipun SPO yang mendukung ketepatan pemberian obat sudah ada dan tersosialisasi, sehingga belum mengetahui pelaksanaan SPO dapat mendukung pelaksanaan ketepatan pemberian obat di Instalasi Farmasi RS Keluarga Sehat.

Selain itu, manajemen juga belum melakukan perbandingan kinerja petugas farmasi berkaitan dengan pelaksanaan SPO, meskipun sudah ada data laporan bulanan belum dianalisis. Hal ini dikarenakan Manager Penunjang Medis double job sehingga umpan balik dari laporan bulanan farmasi tidak ada.

Manajemen rumah sakit juga belum melakukan perbaikan kinerja petugas farmasi berkaitan dengan pelaksanaan SPO dan belum ditemukan konsep perbaikan petugas.Manajemen baru akan berupaya melakukan studi banding, mengikutkan instalasi farmasi ke dalam PSBH, mencari penyebab permasalahan dan membut kebijakan. Upaya tersebut belum didasarkan perbedaan kinerja petugas farmasi pelaksanaan SPO yang salah 
satunya adalah kurangnya konsentrasi petugas farmasi disebabkan ruang pelayanan tidak nyaman.

\section{DAFTAR PUSTAKA}

1. Kepmenkes. Kepmenkes no.129 tahun 2008 Tentang Standar Pelayanan Minimal Rumah Sakit. 1992.

2. Ummu N, Wulandari RD. Benchmarking Mutu Pelayanan Antenatal Care Di Puskesmas Berdasarkan Trilogi Juran. $J A d m$ Kesehat Indones 2014; 2: 263-271.

3. Juran JM. Juran's Quality Handbook. Fifth Edit. New York: The McGrawHill Companies, 1999.

4. Tambunan RM. Pedoman Penyusunan Standard Operating Procedures (SOP). Jakarta: Maiestas Publishing, 2013.

5. Falino DF. Manajemen Karyawan Memimpin Karyawan Dengan Sukses. Jakarta: PT. Suka Buku, 2012.

6. Moeheriyono. Perencanaan Aplikasi dan Pengembangan Indikator Kinerja Utama (IKU) Bisnis dan Publik. Jakarta: PT. Rajagrafindo Persada, 2012.
7. Herlambang S. Cara Mudah Memahami Manajemen Kesehatan dan Rumah Sakit. Yogyakarta: Gosyen Publishing, 2012.

8. Siagian SP. Manajemen Sumber Daya Manusia. Jakarta: Bumi Aksara, 2006.

9. Sunyoto D, Wahyudi D. Manajemen Operasional, Teori, Soal-Jawab, \& Soal Mandiri. Jakarta: PT. Buku Seru, 2011.

10. Wijono, Djoko. Manajemen Mutu Pelayanan Kesehatan Teori, Strategi, dan Aplikasi. Surabaya: Airlangga University Press, 2009. Epub ahead of print 2009.

DOI: 10.1016/j.jss.2015.03.082. 